\title{
Regional Climate Model-Simulated Timing and Character of Seasonal Rains in South America
}

\author{
Sara A. Rauscher* AND AnjI Seth ${ }^{+}$ \\ International Research Institute for Climate and Society, Earth Institute at Columbia University, Palisades, New York \\ BRANT LIEBMANN \\ CIRES Climate Diagnostics Center, Boulder, Colorado
}

Jian-Hua Qian and Suzana J. Camargo

International Research Institute for Climate and Society, Earth Institute at Columbia University, Palisades, New York

(Manuscript received 17 May 2006, in final form 17 October 2006)

\begin{abstract}
The potential of an experimental nested prediction system to improve the simulation of subseasonal rainfall statistics including daily precipitation intensity, rainy season onset and withdrawal, and the frequency and duration of dry spells is evaluated by examining a four-member ensemble of regional climate model simulations performed for the period 1982-2002 over South America. The study employs the International Centre for Theoretical Physics (ICTP) regional climate model, version 3 (RegCM3), driven with the NCEP-NCAR reanalysis and the European Centre-Hamburg GCM, version 4.5. Statistics were examined for five regions: the northern Amazon, southern Amazon, the monsoon region, Northeast Brazil, and southeastern South America. RegCM3 and the GCM are able to replicate the distribution of daily rainfall intensity in most regions. The analysis of the rainy season timing shows the observed onset occurring first over the monsoon region and then spreading northward into the southern Amazon, in contrast to some previous studies. Correlations between the onset and withdrawal date and SSTs reveal a strong relationship between the withdrawal date in the monsoon region and SSTs in the equatorial Pacific, with above-average SSTs associated with late withdrawal. Over Northeast Brazil, the regional model errors are smaller than those shown by the GCM, and the strong interannual variability in the timing of the rainy season is better simulated by RegCM3. However, the regional model displays an early bias in onset and withdrawal over the southern Amazon and the monsoon regions. Both RegCM3 and the GCM tend to underestimate (overestimate) the frequency of shorter (longer) dry spells, although the differences in dry spell frequency during warm and cold ENSO events are well simulated. The results presented here show that there is potential for added value from the regional model in simulating subseasonal statistics; however, improvements in the physical parameterizations are needed for this tropical region.
\end{abstract}

\section{Introduction}

While most climate forecasting efforts have emphasized the prediction of seasonal mean precipitation and

\footnotetext{
* Current affiliation: Earth System Physics Section, Abdus Salam International Centre for Theoretical Physics, Trieste, Italy.

+ Current affiliation: Department of Geography, University of Connecticut, Storrs, Connecticut.
}

Corresponding author address: Dr. Sara A. Rauscher, Earth System Physics Section, Abdus Salam International Centre for Theoretical Physics, Trieste, Italy.

E-mail: srausche@ictp.it

DOI: 10.1175/MWR3424.1

(C) 2007 American Meteorological Society temperature, knowledge of the timing and character of the rainy season may be of more practical use to stakeholders and decision makers, especially for agricultural applications (Lemos et al. 2002). Traditionally, ensembles of general circulation model (GCM) simulations driven by persisted and forecast sea surface temperatures (SSTs) are used to make these seasonal forecasts (e.g., Barnston et al. 2003; Palmer et al. 2004). For South America, GCMs have shown some skill in predicting seasonal precipitation because of the strong relationships between SST anomalies and rainfall, particularly over Northeast Brazil (Nobre et al. 2001; Moura and Hastenrath 2004). However, the coarse horizontal resolution of GCMs limits their ability to 
resolve local climatological features induced by smaller-scale variations in topography and land use, which in turn may affect rainfall. This may be of particular importance for South America because of the presence of the South American low-level jet (SALLJ). Located just to the east of the Andes Mountains, the jet is a mesoscale feature that plays a strong role in transporting moisture from tropical to subtropical South America (Virji 1981; Paegle 1998; Berbery and Barros 2002; Marengo et al. 2002, 2004; Vera et al. 2006). Regional climate models can be used to identify these mesoscale dynamical processes (i.e., "dynamical downscaling") because they are run at high resolutions (typically 5-100 km) over smaller areas. We therefore pose the question: Can a regional model nested in a driving GCM provide improved spatial and temporal climate information, particularly with regard to higherfrequency precipitation statistics such as rainy season onset and demise, dry spells, and daily rainfall intensity?

The correct simulation of daily precipitation in climate models has been problematic. Early studies showed that while models produced seasonal precipitation patterns and totals similar to observations, these values were the product of compensating errors in the frequency and intensity of precipitation, with too much low intensity precipitation (i.e., drizzle) occurring too frequently (Mearns et al. 1995). However, some recent regional modeling studies for South America have shown improvements in the simulation of daily precipitation. Seth et al. (2004) examined the frequency and intensity of daily precipitation events for two extreme seasons, January-May 1983 (warm ENSO event) and January-May 1985 (cold ENSO event) using a regional model (RegCM2) driven with both the National Centers for Environmental Prediction-National Center for Atmospheric Research (NCEP-NCAR) reanalysis and a GCM (CCM3) for tropical and subtropical South America. While RegCM2 slightly overestimated the frequency of small precipitation events, it was nevertheless able to capture the shift in the distribution of daily precipitation intensity between the two extreme years. Using the NCEP Regional Spectral Model (RSM) driven with multiple ensemble members of a GCM, Sun et al. (2005) found that the RSM correctly simulated the distribution of daily precipitation intensity and other subseasonal characteristics of precipitation such as the frequency and duration of dry spells over Northeast Brazil. In an operational setting, dynamically downscaled forecasts produced with the RSM showed higher skill than the driving GCM for some seasons (Sun et al. 2006).
In addition to intensity and frequency of precipitation, some knowledge of the timing of the rainy season [i.e., onset and withdrawal (demise)], would be beneficial for applications in agriculture and water resource management. Liebmann and Marengo (2001) showed that for the Amazon, SST anomalies influence seasonal precipitation through changes in the timing of the rainy season, rather than through changes in the overall precipitation rate. In a companion paper to this work, Seth et al. (2006) found that the regional model used here can reproduce seasonal precipitation anomalies related to SST forcing in the tropical Pacific and Atlantic Oceans. Therefore, there is reason to believe that the nested model could provide useful information regarding the timing of the rainy season.

To date, numerous studies have calculated rainy season onset and withdrawal over tropical and subtropical South America with qualitatively similar results using observed data (Kousky 1988; Horel et al. 1989; Liebmann and Marengo 2001; Marengo et al. 2001; González and Barros 2002; Wang and Fu 2002; Zhou and Lau 2002). In general, onset is led by the annual cycle of radiation across the continent (Horel et al. 1989). Onset occurs first (and rapidly) in late August over the western Amazon, when there is a reversal of low-level cross-equatorial flow from the south to the north (Horel et al. 1989; Wang and Fu 2002). The established view from many of these studies is that onset dates increase both southward and eastward from the western Amazon, although Liebmann and Marengo (2001) and Liebmann et al. (2007) note a reversal of onset from central Brazil to the Amazon. The subtropical plains experience onset on average in October, with the formation of a northwest-southeastoriented band of convection known as the South Atlantic convergence zone (SACZ; Kodama 1992, 1993; Carvalho et al. 2004). During the austral summer, deep convection is present over most of the continent from the equator to $20^{\circ} \mathrm{S}$, with the exception of the eastern Amazon and Northeast Brazil. This main phase of the South American monsoon system (SAMS) is characterized by the presence an upper-level anticyclone (the Bolivian high) located at $15^{\circ} \mathrm{S}, 65^{\circ} \mathrm{W}$ and a trough over Northeast Brazil (Zhou and Lau 1998), as illustrated in Fig. 1 of Nogues-Paegle et al. (2002). As the austral autumn approaches, convection spreads into the eastern Amazon and Northeast Brazil, while elsewhere over the continent, the monsoon begins to retreat northwestward at a slower pace than onset (Marengo et al. 2001). Over northern Northeast Brazil, the main rainy season extends from January to May, peaking in March and April when the ITCZ is at its 


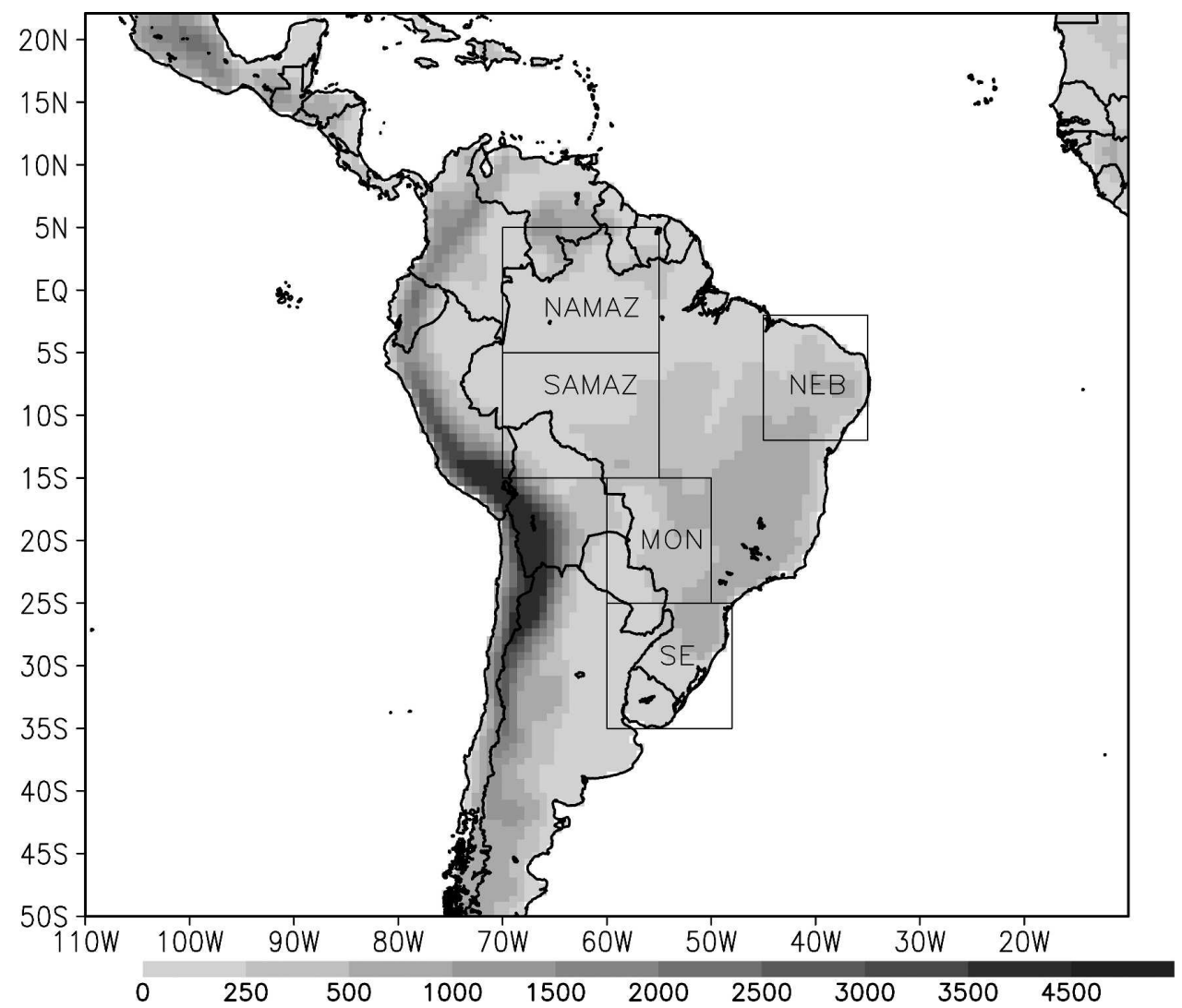

FIG. 1. RegCM3 domain used in the present study: $111 \times 138$ grid points, $80-\mathrm{km}$ horizontal resolution. Shaded contours show topography in $\mathrm{m}$. Boxes indicate regions used in calculation of statistics presented (land only).

southernmost position, and high SSTs are present in the western equatorial Atlantic (Hastenrath and Heller 1977).

Here we present results from a retrospective study that spans 20 rainy seasons between January 1982 and December 2002, in which we examine the potential of an experimental nested prediction system to improve the simulation of subseasonal rainfall statistics over the driving GCM. The present study employs the International Centre for Theoretical Physics (ICTP) regional climate model version 3 (RegCM3) driven with both the NCEP-NCAR reanalysis (NNRP; Kalnay et al. 1996) and three ensemble members of the European Centre-Hamburg GCM (ECHAM GCM), version 4.5 (Roeckner et al. 1996; referred to as the GCM in the text). We examine the model skill in simulating higherfrequency rainfall statistics including the distribution of daily rainfall intensity, rainy season onset and withdrawal, and the frequency and duration of dry spells over five regions: the northern Amazon, southern Amazon, Northeast Brazil, the monsoon region, and southeastern South America.

\section{Methods}

\section{a. Experiment design}

A set of four simulations were performed. One simulation was forced with initial and lateral boundary conditions from NNRP (NN-RegCM) while the other three were initialized using three ensemble members of the GCM (EC-RegCM). The simulations were run during 1982-2003. We excluded 2003 from this analysis due to some missing data in one of the observational datasets (discussed below). The model topography and domain for these experiments are shown in Fig. 1. The domain is fairly large, encompassing most of tropical and subtropical South America, extending from $50^{\circ} \mathrm{S}-22^{\circ} \mathrm{N}$ to $110^{\circ}-10^{\circ} \mathrm{W}$ with a horizontal grid increment of $80 \mathrm{~km}$. The large domain was chosen because test simulations revealed that a large domain extending into the Atlantic Ocean improved the simulation of the ITCZ (Rauscher et al. 2006).

Also indicated in Fig. 1 are the areas used for the analysis of the subseasonal rainfall statistics. All regions are defined over land only. The Amazon basin was split 

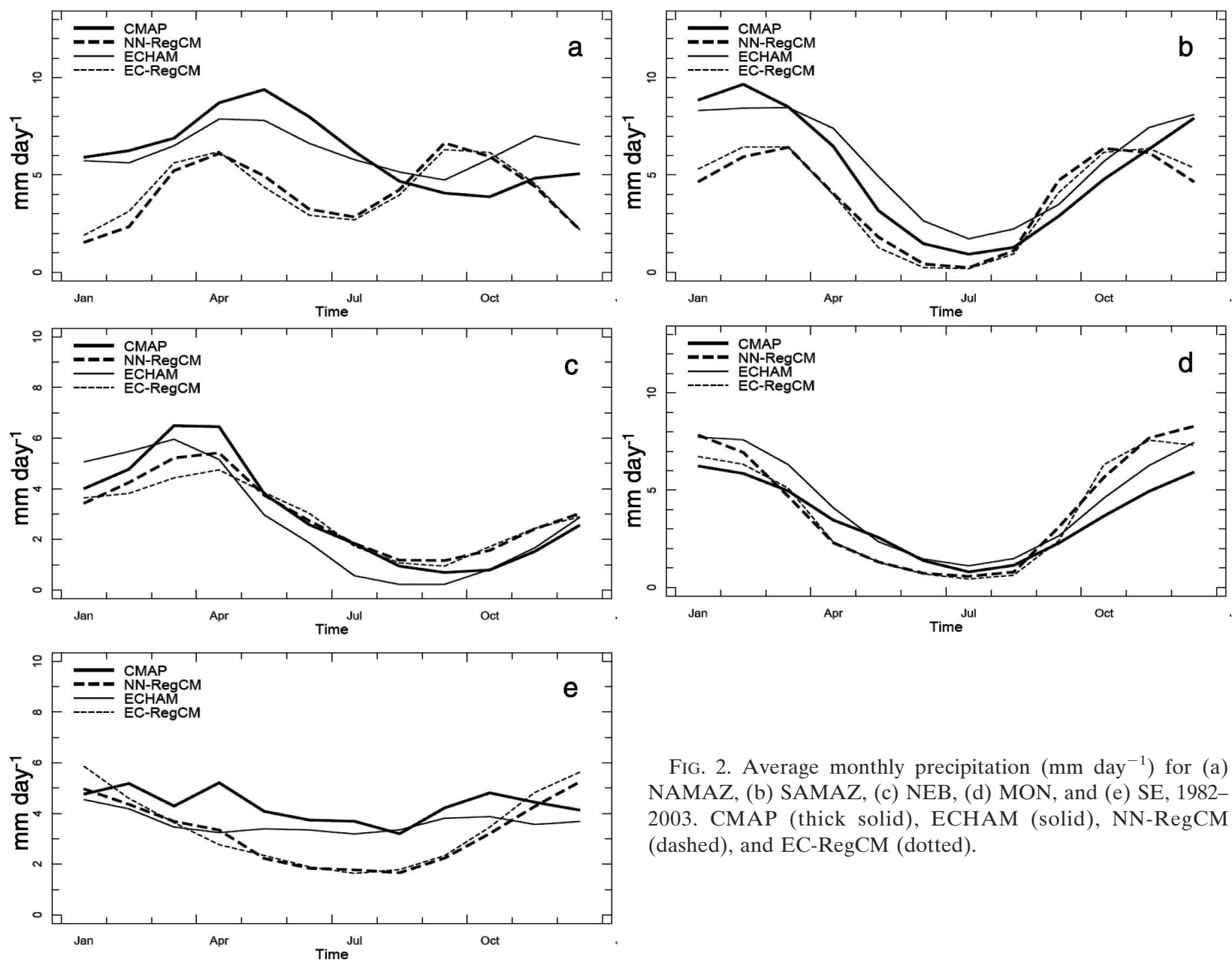

FIG. 2. Average monthly precipitation $\left(\mathrm{mm} \mathrm{day}^{-1}\right)$ for (a) NAMAZ, (b) SAMAZ, (c) NEB, (d) MON, and (e) SE, 19822003. CMAP (thick solid), ECHAM (solid), NN-RegCM (dashed), and EC-RegCM (dotted).

into two regions, the northern Amazon (NAMAZ: $5^{\circ} \mathrm{N}-5^{\circ} \mathrm{S}, 70^{\circ}-55^{\circ} \mathrm{W}$ ) and the southern Amazon basin (SAMAZ: $5^{\circ}-15^{\circ} \mathrm{S}, 70^{\circ}-55^{\circ} \mathrm{W}$ ) because the annual cycle of precipitation varies in these areas, with NAMAZ experiencing a precipitation maximum in May (Fig. 2a), while SAMAZ has its maximum in February (Fig. 2b). Northeast Brazil (NEB) is defined as $12^{\circ}-2^{\circ} \mathrm{S}, 45^{\circ}-35^{\circ} \mathrm{W}$. The monsoon region (MON) extends from $25^{\circ}-15^{\circ} \mathrm{S}$ to $60^{\circ}-50^{\circ} \mathrm{W}$, which includes portions of Bolivia, Paraguay, and west-central Brazil. The southeastern South America region (SE) is defined as $35^{\circ}-25^{\circ} \mathrm{S}, 60^{\circ}-48^{\circ} \mathrm{W}$, and covers parts of Uruguay, southern Brazil, and northeastern Argentina. The western boundary of the MON and SE regions was limited to $60^{\circ} \mathrm{W}$ due to missing data west of $60^{\circ} \mathrm{W}$ from the daily precipitation dataset of Liebmann and Allured (2005). The MON and SE regions were defined to capture the different precipitation regimes over the La Plata River basin (located in northeastern Argentina, southern Brazil, southeastern Bolivia, Paraguay, and
Uruguay). Berbery and Barros (2002, their Fig. 7) show that the northern part of the river basin has a clear maximum in precipitation in the austral summer associated with the SAMS. South of this region, the annual cycle is damped, partly due to midlatitude disturbances that occur during the austral winter.

For an examination of model performance in simulating subseasonal statistics during years of strong SST anomalies, when predictive skill would be expected to be high, four warm ENSO events (hereafter warm events) and four cold ENSO events (hereafter cold events) were chosen based on the National Oceanic and Atmospheric Administration (NOAA) Climate Prediction Center's oceanic Niño index (Kousky and Higgins 2007). The index is a 3-month running mean of SST anomalies in the Niño-3.4 region $\left(5^{\circ} \mathrm{N}-5^{\circ} \mathrm{S}, 120^{\circ}-\right.$ $170^{\circ} \mathrm{W}$ ) based on the 1971-2000 base period. Cold and warm episodes are defined when the threshold of $\pm 0.5^{\circ} \mathrm{C}$ is met for a minimum of five consecutive overlapping seasons [e.g., December-February (DJF), 
January-March (JFM), February-April (FMA), March-May (MAM), and April-June (AMJ)]. For the 1982-2002 period, and considering the austral summer season (DJF), the four strongest warm events occurred in 1982/83, 1986/87, 1991/92, and 1997/98, while the four strongest cold events were recorded in 1984/85, 1988/89, 1998/99, and 1999/2000. Composites of these events are used to describe the nature of precipitation during warm and cold events.

\section{b. ICTP RegCM3}

The ICTP RegCM3 (Pal et al. 2007) is a limited-area model built around the hydrostatic dynamical component of the fifth-generation Pennsylvania State University-NCAR Mesoscale Model (MM5; Grell et al. 1994). The model is compressible, based on primitive equations, and employs a terrain-following $\sigma$-vertical coordinate. The limited-area model is driven by atmospheric lateral boundary conditions. Unresolved precipitation processes are represented with the cumulus parameterization scheme of Grell (1993) with the Arakawa-Schubert closure (Arakawa and Schubert 1974). Further details regarding the physical parameterizations can be found in (Pal et al. 2007) and in Seth et al. (2006).

\section{c. ECHAM GCM}

The ECHAM GCM is an atmospheric GCM with a hybrid sigma-pressure vertical coordinate. It has a horizontal T42 spectral resolution ( $2.8^{\circ}$ latitude-longitude) and has 19 vertical levels, with the top extending to 10 $\mathrm{hPa}$. The mass flux scheme of Tiedtke (1989) is employed for both deep and shallow convection. Radiative fluxes in the model follow a modified version of the European Centre for Medium-Range Weather Forecasts (ECMWF) formulation of Fouquart and Bonnel (1980) and Morcrette et al. (1986). For full details on the GCM, readers may refer to Roeckner et al. (1996).

A 24-member ensemble of +50 -yr integrations (1950-present) using observed monthly SST has been performed at the International Research Institute for Climate and Society (IRI). The ensemble members were constructed using two methods: for some members the start dates were varied, while other ensemble members had the same start date but were perturbed with some noise in the atmospheric wind field so that their solutions would diverge (D. DeWitt 2006, personal communication). Three of these ensemble members were used here; one of the ensemble members was chosen based on a domain choice experiment (Rauscher et al. 2006); no particular selection criteria were applied to the other two ensemble members (i.e., the ensemble members were chosen at random).

\section{d. Data}

Model initial and lateral boundary conditions were created with three ensemble members of the GCM and NNRP (Kalnay et al. 1996). Monthly SSTs were obtained from the NOAA optimum interpolation (OI) SST analysis (version 2) of Reynolds et al. (2002). The monthly SSTs are linearly interpolated to daily values in the model. The model-output precipitation is compared with two datasets: the Climate Prediction Center Merged Analysis of Precipitation (CMAP; Xie and Arkin 1996) and daily precipitation grids for South America produced by Liebmann and Allured (2005). A blended product of global satellite and gauge data, CMAP data are available as monthly averages on a $2.5^{\circ}$ latitude-longitude grid. The CMAP data are used in section 2 to evaluate the models' annual cycle. Daily precipitation data for South America are supplied via a gridded dataset $\left(1^{\circ}\right.$ latitude-longitude grid) derived from station observations (Liebmann and Allured 2005). Gathered from more than 15 different sources, these data include 7900 station locations during 19402003 , although data for all stations were not available for all years. Quality control issues such as missing and duplicate data, outliers, and collection and recording times have been examined and corrections have been made. Station density varies throughout the years; it is highest and most stable in the 1970s and 1980s and decreases somewhat through the 1990s (this varies with region, however). The NEB and SE regions have the greatest number of stations, while the MON region has the lowest density of stations when considering our five regions. With the exception of a few grid cells in NEB, most data were missing for 2003, so the 2002-03 rainy season was not included in our subseasonal analysis. All of the subseasonal analyses (sections $3 b, c, d$ ) were performed using these daily data.

\section{Results}

\section{a. Annual cycle of precipitation}

Here we briefly describe the annual cycle of precipitation for the five regions as background for the following discussion. The model output is compared with monthly observations from the CMAP dataset. For a full evaluation of model performance at seasonal and interannual time scales, the reader is referred to Seth et al. (2006).

In NAMAZ (Fig. 2a), precipitation is at a maximum 
when the SAMS retreats equatorward in April and May. The CMAP observations show a maximum near $10 \mathrm{~mm} \mathrm{day}^{-1}$ in May. The GCM simulates the annual cycle well, although its amplitude is damped somewhat in comparison to the observations. Li et al. (2006) showed that many GCMs have a tendency to underestimate precipitation over the Amazon region. This may be partly due to the smoothing of the Andes in the GCM simulations; there is a spatial maximum in precipitation in the western Amazon that is likely topographically forced (Figueroa and Nobre 1990). In NNRegCM and EC-RegCM, precipitation peaks too early in April and is less than the observed. There is also a secondary precipitation maximum in September that occurs in response to the semiannual solar forcing in the region; this is also seen in some GCM simulations (Bonan et al. 2002; M. Rojas, A. Seth, and S. Rauscher 2006, unpublished manuscript). The presence of a weaker low-level circulation in the regional model may help to account for this increased response to the solar forcing. For SAMAZ (Fig. 2b), the observations show a maximum in February and a minimum in July. The GCM simulates the annual cycle fairly well, although there is no clear maximum in February. Both NNRegCM and EC-RegCM show a semiannual cycle (also seen in NAMAZ), with a secondary precipitation maximum occurring in October and less-than-observed precipitation during the main core of the rainy season, December-March.

Over NEB, the observations indicate that precipitation is at a maximum during the austral autumn (MAM), with precipitation rates averaging close to 7 $\mathrm{mm} \mathrm{day}^{-1}$. The driest part of the year occurs during the austral winter and spring. The GCM shows good agreement in the amplitude of the annual cycle, but the timing is slightly shifted so that the maximum and minimum appear to occur slightly earlier than in the observations. The regional model displays a slightly damped amplitude, but the timing agrees well with the observations.

All of the models perform well in MON (Fig. 2d), as they capture the precipitation maximum in December and January associated with the SAMS and the minimum in July. Compared to MON, SE (Fig. 2e) shows a small annual cycle, with differences of only 1-2 mm day $^{-1}$ between the austral summer and winter. The GCM reduces the annual cycle further in the region, while both NN-RegCM and EC-RegCM show a more marked difference in precipitation between the summer and winter than is seen in the observations. In particular, the regional model is drier by approximately $2 \mathrm{~mm}$ day $^{-1}$ during July and August. In the regional model, this reduced precipitation is related to weaker than ob- served northerly flow over Paraguay that provides the moisture source for precipitation systems (Vera et al. 2002).

\section{b. Distribution of daily rainfall intensity}

To calculate daily precipitation intensities, the rainy season was first defined based on average onset and withdrawal dates for each region, rounded to the whole month (Table 1). The daily intensities were then computed objectively for each region's rainy season. For all of the subseason analysis (sections $3 \mathrm{~b}-\mathrm{d}$ ), the daily data of Liebmann and Allured (2005) were used. Figure 3 shows the distribution of rainfall intensity for the five regions defined in section 2a for 1982-2002.

In all of the regions except for NEB, the observed modal intensity (the category with the maximum number of events) is in the $5-10 \mathrm{~mm}$ day $^{-1}$ category. This pattern is replicated by the regional model, except in NAMAZ where the regional model overestimates events in the three lowest categories compared to the observations. For NAMAZ, the absence of more intense events in the regional model translates into an underestimation of seasonal precipitation (Fig. 2a). The GCM also captures this observed modal frequency with the exception of SE, where the GCM simulates more events in the $0-1 \mathrm{~mm}^{-1 a y}{ }^{-1}$ category than in the 5-10 $\mathrm{mm}$ day $^{-1}$ category.

For NEB, most precipitation events are in the 2.5-5 mm day ${ }^{-1}$ category. Both the NN-RegCM and ECRegCM have the correct modal frequency. However, the regional model underestimates the number of norainfall $\left(0-1 \mathrm{~mm}^{-1 a y}{ }^{-1}\right)$ and heavy rainfall $(10-20 \mathrm{~mm}$ day $^{-1}$ ) events. In contrast, the GCM simulates more no-rainfall and heavy rainfall days compared to the observations.

To assess model performance during years of strong forcing, the distributions of daily rainfall intensity during the rainy season in warm and cold ENSO episodes were calculated for the five regions. We limit the discussion to NEB because the ENSO signal is well established in this region (Ropelewski and Halpert 1987, 1989). Over NEB (Fig. 4), there is a clear shift toward smaller events during warm events (Fig. 4b) and larger events during cold events (Fig. 4a). While this relative shift in intensity is captured by the models, there are obvious differences between the models and the observations. For warm events, the largest frequency occurs in the no-rain category for the observations and the GCM, while NN-RegCM and EC-RegCM have a modal frequency in the $1-2.5 \mathrm{~mm} \mathrm{day}^{-1}$ category. In cold events the modal frequency is $5-10 \mathrm{~mm} \mathrm{day}^{-1}$ for the observations and the GCM, and $2.5-5 \mathrm{~mm} \mathrm{day}^{-1}$ for 

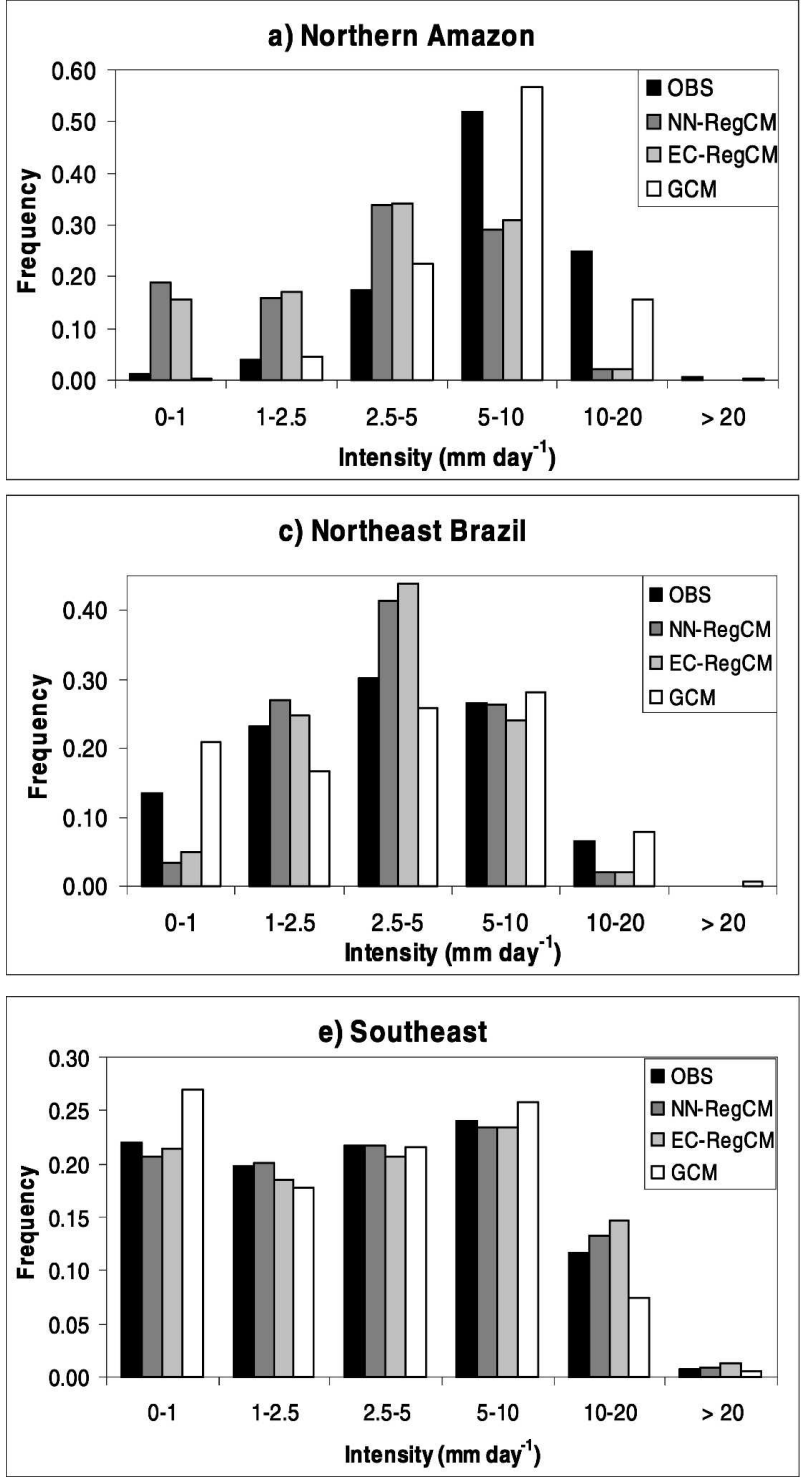

the regional model, regardless of lateral boundary forcing.

\section{c. Onset, demise, and length of rainy season}

To calculate onset over South America, most studies have employed thresholds of precipitation (Marengo et al. 2001; Zhou and Lau 2002) or outgoing longwave radiation (OLR; Kousky 1988; González and Barros 2002) as a proxy for precipitation. Since these methods use the same threshold everywhere (e.g., $6 \mathrm{~mm} \mathrm{day}^{-1}$ ) to define onset and withdrawal everywhere, the definitions are nonlocal and the onset and withdrawal date may change substantially with the use of a different value. Therefore, onset and withdrawal dates were cal-
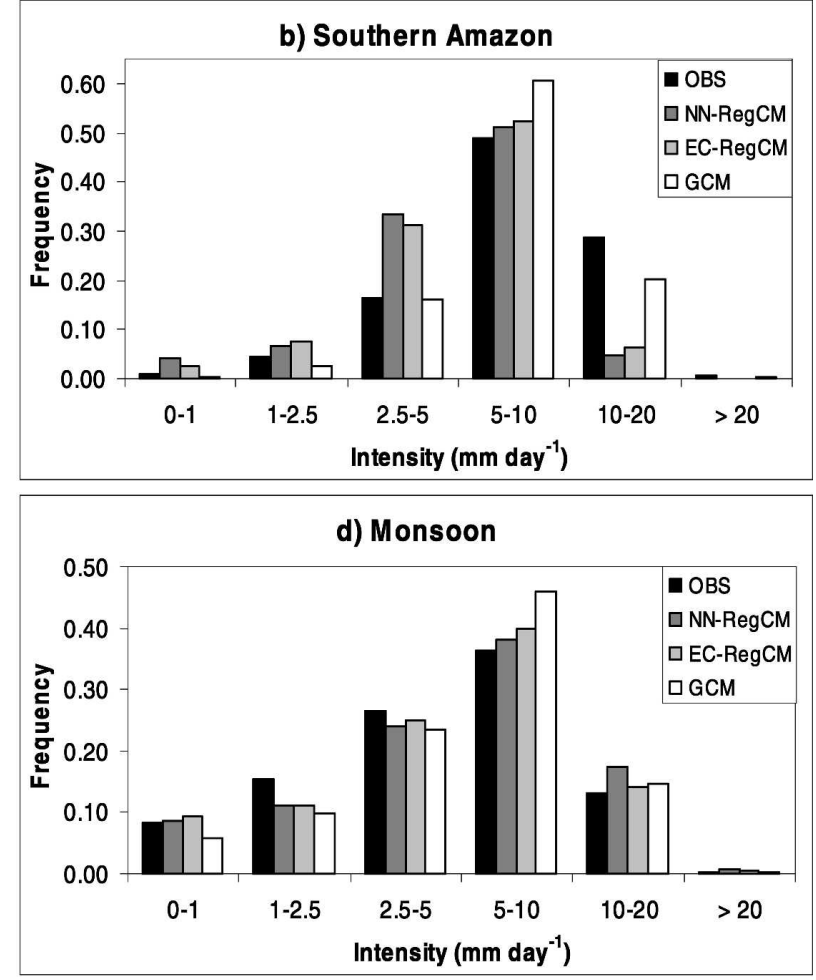

FIG. 3. Distribution of daily rainfall intensity $\left(\mathrm{mm} \mathrm{day}^{-1}\right)$ during the rainy season for (a) NAMAZ, (b) SAMAZ, (c) NEB, (d) MON, and (e) SE for 1982-2002. Obs (black), NN-RegCM (dark gray), EC-RegCM (light gray), GCM (white).

culated in the method described by Liebmann and Marengo (2001):

$$
A(\text { day })=\sum_{n=\text { day }_{0}}^{\text {day }}[R(n)-\bar{R}] .
$$

For each region, the difference between the daily precipitation $[R(n)]$ and the long-term (1982-2002) daily mean precipitation $(\bar{R})$ was summed, beginning during the dry season ( day $_{0}, 1$ July). The date on which this sum [A(day), or anomalous accumulation] is a minimum is the date of onset, while the date of the maximum sum marks the rainy season withdrawal. This method is both objective and defined locally, that is, 

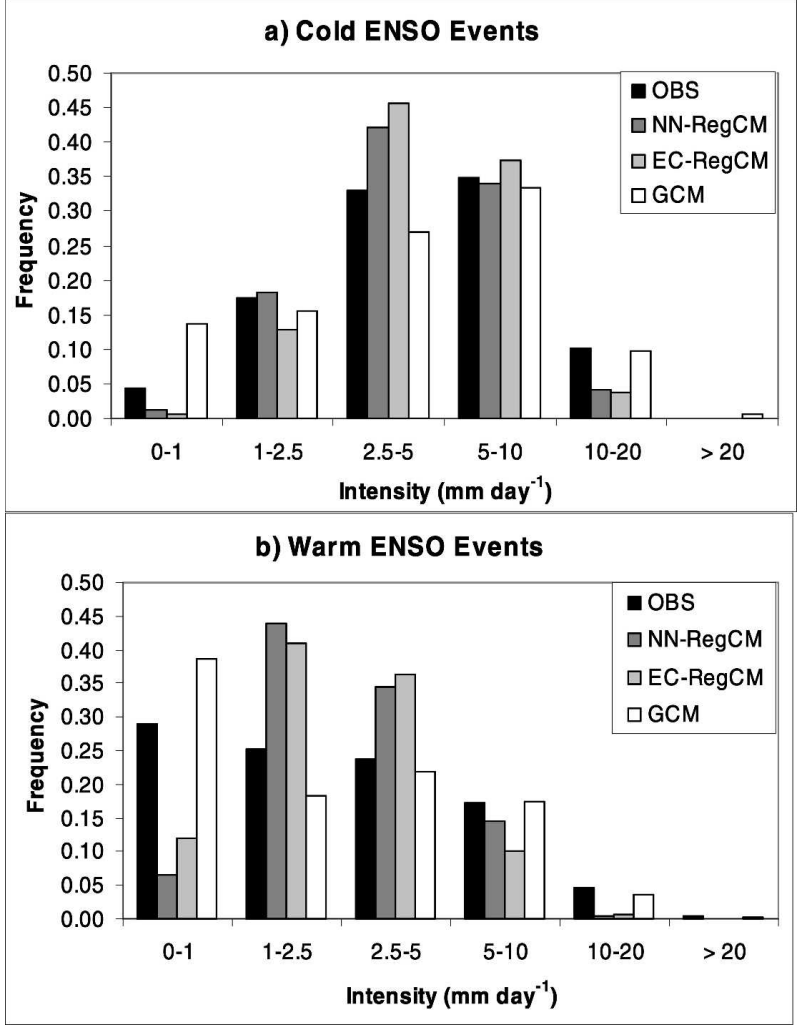

FIG. 4. Distribution of daily rainfall intensity $\left(\mathrm{mm} \mathrm{day}^{-1}\right)$ during the rainy season for NEB for (a) cold and (b) warm ENSO events, 1982-2002. Shading as in Fig. 3.

based on the climate of the area of interest. However, the date of onset can vary slightly depending on the start date of the summation.

In the following sections we discuss the model performance in calculating the date of onset and withdrawal and length of the rainy season. We focus the discussion on SAMAZ, MON, and NEB because of the presence of distinct wet and dry seasons.

\section{1) Southern Amazon And monsoon Regions}

Figure 5 shows the average onset date (Fig. 5a), withdrawal date (Fig. 5b), and length of the rainy season (Fig. 5c) for SAMAZ and MON. These dates and their standard deviations are also listed in Table 1. The observations show the rainy season beginning almost simultaneously in the SAMAZ and the MON regions in the middle of October, with onset actually occurring slightly earlier in the MON region. This is consistent with Liebmann and Marengo (2001) and Liebmann et al. (2007), who found onset occurring in October in the MON region, and then later in the Amazon (their Fig. $3)$. Withdrawal occurs during April, first over the MON region (14 April) and then about 11 days later (25 April) over the SAMAZ.
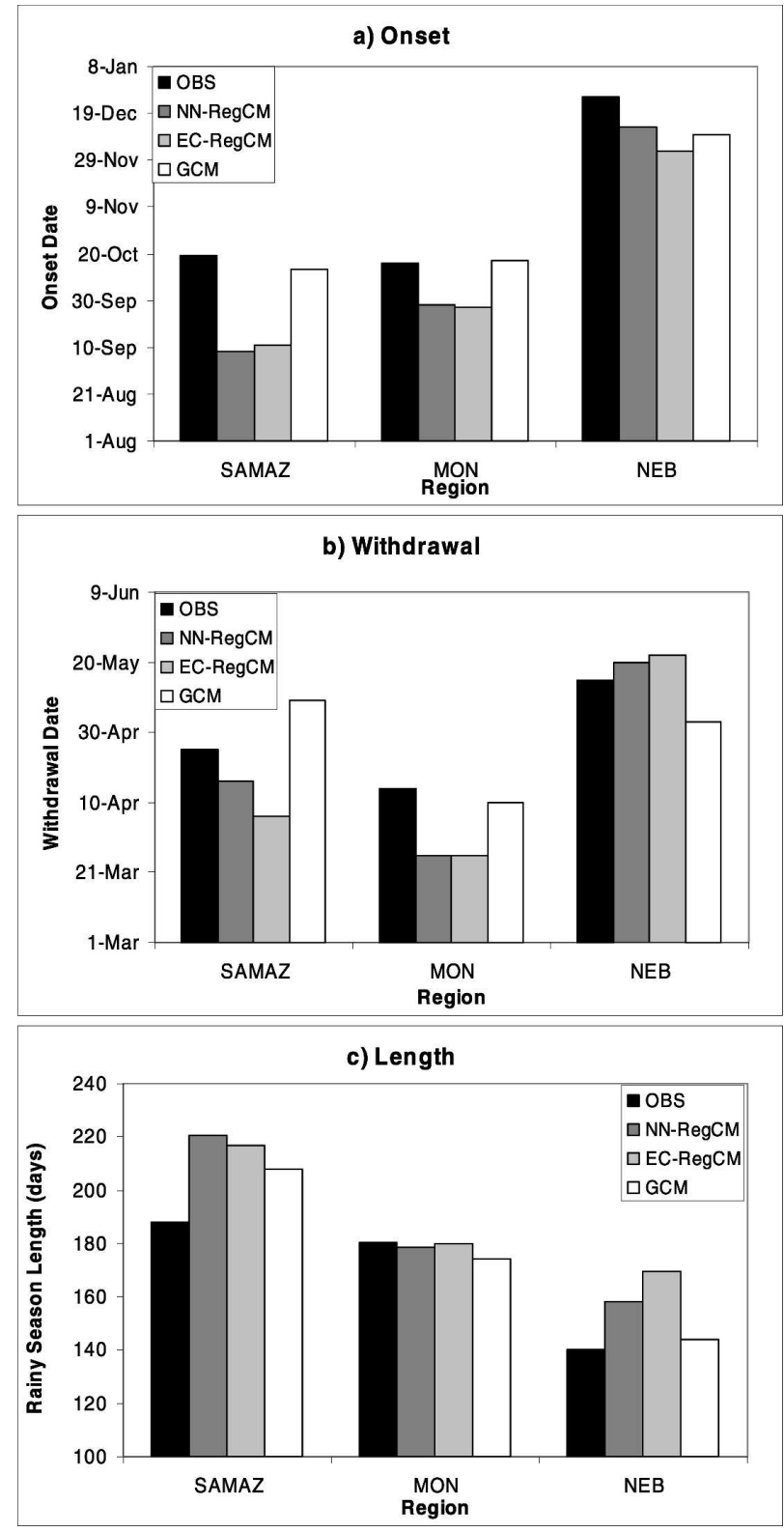

FIG. 5. Average date of (a) onset, (b) withdrawal, and (c) length of rainy season, 1982-2002. Shading as in Fig. 3.

The regional model simulations are quite similar to each other in terms of onset and withdrawal dates over the SAMAZ and the MON region. The observed nearsimultaneous onset seen over the SAMAZ and the $M O N$ region is absent. The rainy season begins first over the SAMAZ in the second week of September, and then progresses to the MON region at the end of September. In both areas, onset is approximately one month early in the regional model simulations compared to the observations. The GCM appears to outperform the regional model (regardless of lateral 
TABLE 1. Average date [std dev (days)] of onset, withdrawal, and length of rainy season (days).

\begin{tabular}{|c|c|c|c|c|}
\hline Region & Obs & NN-RegCM & EC-RegCM & GCM \\
\hline \multicolumn{5}{|l|}{ Onset } \\
\hline SAMAZ & 19 Oct (13) & 8 Sep (8) & 11 Sep (5) & $13 \operatorname{Oct}(9)$ \\
\hline MON & 16 Oct (25) & 28 Sep (11) & 27 Sep (5) & 17 Oct (10) \\
\hline NEB & $26 \operatorname{Dec}(25)$ & $13 \operatorname{Dec}(40)$ & $3 \operatorname{Dec}(40)$ & $10 \operatorname{Dec}(20)$ \\
\hline \multicolumn{5}{|l|}{ Withdrawal } \\
\hline SAMAZ & $25 \operatorname{Apr}(11)$ & $16 \operatorname{Apr}(8)$ & 6 Apr (3) & 9 May (5) \\
\hline MON & 14 Apr (21) & $26 \operatorname{Mar}(18)$ & 26 Mar (12) & 10 Apr (8) \\
\hline NEB & 15 May (23) & 20 May (23) & 22 May (27) & 3 May (20) \\
\hline \multicolumn{5}{|l|}{ Length } \\
\hline SAMAZ & 187 (17) & $220(13)$ & $216(5)$ & $208(11)$ \\
\hline MON & $180(34)$ & $178(25)$ & $179(12)$ & $174(11)$ \\
\hline NEB & $140(39)$ & $158(56)$ & $169(62)$ & $143(33)$ \\
\hline
\end{tabular}

boundary forcing), as the onset time is very similar to the observed for both regions.

Both the NN-RegCM and EC-RegCM have withdrawal occurring too early in both regions, although the EC-RegCM appears to have a stronger early bias. The GCM shows a late withdrawal over the SAMAZ. All of the models overestimate the length of the rainy season in the SAMAZ, but the length is better simulated over MON, with differences of a week or less between the models and the observations.

Figures 6 and 7 show the plots of yearly onset and withdrawal dates for the SAMAZ and MON regions, respectively. Considering the observations, variability over the SAMAZ is the smallest, with onset and with-

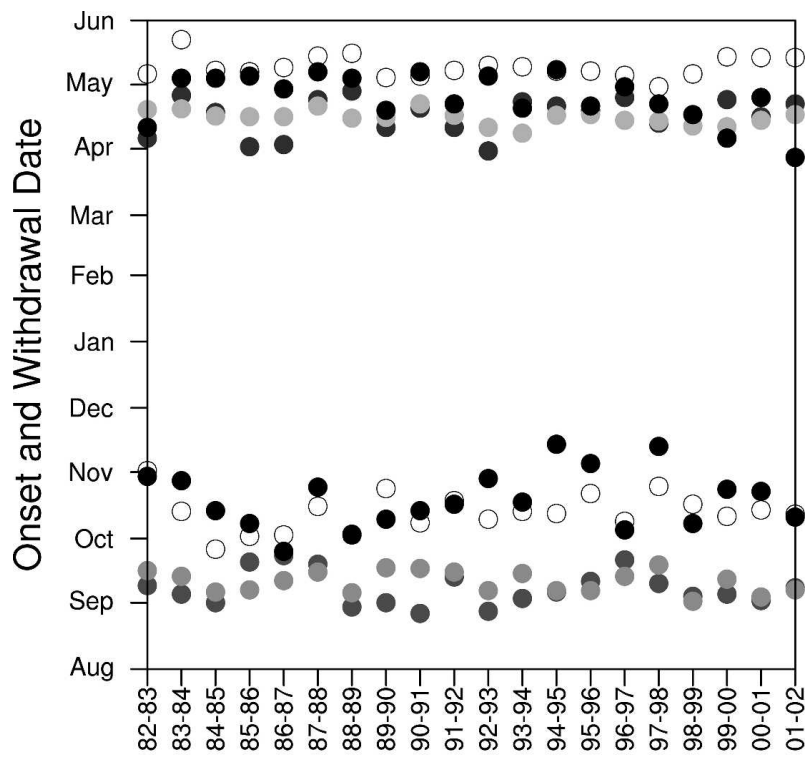

\section{Year}

FIG. 6. Yearly onset and withdrawal dates for SAMAZ, 19822002. Observations (black circles), NN-RegCM (dark gray circles), EC-RegCM (light gray circles), and GCM (open circles). drawal dates varying by an average of two weeks. Variability is higher over the MON region, although this may be partly due to the presence of three years with anomalously late onset dates in 1985-86, 1986-87, and 1999-2000. The late onset in 1985-86 was due to two breaks that occurred in mid-November and early December. In 1986-87, precipitation occurred throughout the austral spring, but there were no large events to mark onset. Finally, in 1999-2000, a break throughout most of November moved the date of onset from early November to December. The presence of these breaks may be indicative of fewer midlatitude disturbances that help to start and organize convection in the SACZ (Gan et al. 2004; Liebmann et al. 1999), and of a lessactive SACZ in general. In both SAMAZ and MON,

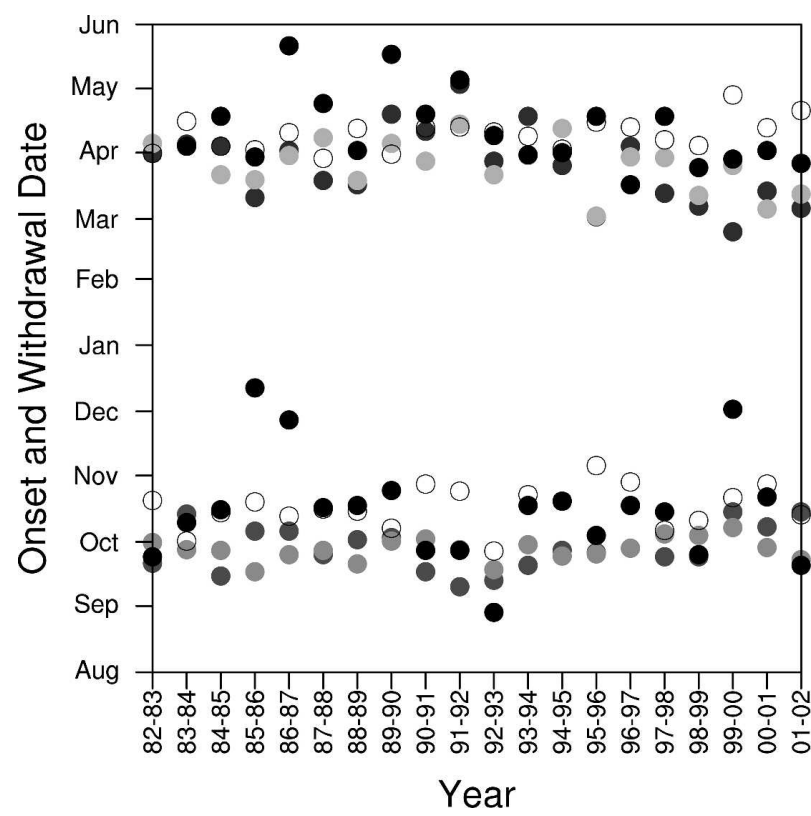

FIG. 7. Yearly onset and withdrawal dates for MON, 1982-2002. Shading as in Fig. 6. 
TABLE 2. Correlations between modeled and observed onset and withdrawal date. Entries in boldface are significant at the 0.10 level.

\begin{tabular}{lccr}
\hline \hline SAMAZ & NN-RegCM & EC-RegCM & GCM \\
\hline Onset & -0.18 & 0.15 & $\mathbf{0 . 5 3}$ \\
Withdrawal & -0.04 & 0.28 & 0.03 \\
\hline \multicolumn{1}{c}{ MON } & NN-RegCM & EC-RegCM & GCM \\
\hline Onset & $\mathbf{0 . 5 3}$ & 0.04 & 0.18 \\
Withdrawal & $\mathbf{0 . 4 2}$ & $\mathbf{0 . 4 1}$ & $-\mathbf{0 . 3 9}$ \\
\hline \multicolumn{1}{c}{ NEB } & NN-RegCM & EC-RegCM & GCM \\
\hline Onset & $\mathbf{0 . 5 7}$ & $\mathbf{0 . 5 6}$ & 0.22 \\
Withdrawal & $\mathbf{0 . 8 0}$ & $\mathbf{0 . 6 5}$ & $\mathbf{0 . 7 9}$ \\
\hline
\end{tabular}

onset date is slightly more variable than withdrawal date. This same result was noted by Gan et al. (2004), who identified onset and withdrawal dates, for westcentral Brazil, an area that includes part of our SAMAZ and $\mathrm{MON}$ regions.

For the regional model, the averages discussed in the previous section are borne out by the model performance in individual years, as both the regional models shows onset earlier than the observed in almost every year, particularly for the SAMAZ. In fact, when considering correlations between the observed onset dates and the model results, none of the models perform particularly well in the SAMAZ region, as seen in the correlations in Table 2. The regional model improves when considering the MON region, however, although the NN-RegCM performs better than the EC-RegCM. All of the models display less interannual variability than the observed data, as evidenced by their smaller standard deviations. In addition, the three years with late onset dates in the MON region are not captured by any of the models.

For the MON region, the observed difference in onset date for warm events and cold events is one week, with onset occurring earlier during warm events (in contrast to SAMAZ). Again, this difference is much less than the standard deviation of onset, 25 days. Correlations performed with SSTs showed no strong associations between onset date and SSTs in either the Atlantic or Pacific Oceans (not shown). However, for withdrawal, a larger difference of three weeks, with withdrawal occurring later in warm events and earlier in cold events, is present in the observations. Note that this difference is largely attributable to late withdrawal in warm events, rather than early withdrawal in cold events. The late withdrawal during warm events is captured by both the regional models, but not by the GCM.

This relationship between the timing of the rainy season in the MON region and Pacific SSTs is interesting, as this is an area where strong correlations between Pacific SSTs and rainfall have not been previously found (Ropelewski and Halpert 1987; Grimm et al. 2000; Gan et al. 2004). To explore this relationship further, the withdrawal date for each year was correlated with monthly SSTs. In the observations, weak positive correlations $(\sim 0.4)$, meaning that above-verage SSTs are associated with late withdrawal, appear in the central and eastern Pacific as early as October. However, the strongest correlations are seen in DecemberMarch. As an example, the correlations for March are shown in Fig. 8. These correlations are statistically significant (using a Student's $t$ test) for the NN-RegCM and the EC-RegCM, although they are weaker than observed. This relationship is not found in the GCM, and in fact the correlations are negative to those that are found in the observed data and the regional model. Seth et al. (2006) showed that the GCM does not capture the observed ENSO-related signal in the subtropical South Atlantic during warm events, and this may help to explain the lack of relationship between withdrawal date and Pacific SST anomalies in the GCM.

\section{2) Northeast BrazIL}

Over NEB, the main rainy season extends from January to May, peaking in March and April when the ITCZ is at its southernmost position (Hastenrath and Heller 1977; Kousky 1979), and high SSTs are present in the western equatorial Atlantic. As shown in Fig. 5, the average observed date of onset is 26 December; the two regional models place onset about two to three weeks early, as does the GCM. Withdrawal occurs in the middle of May. Both EC-RegCM and NN-RegCM are approximately one week late of the observed withdrawal, while the GCM is about two weeks early on average. The early onset and late withdrawal seen in the regional model result in a rainy season that is too long. Although the timing of the rainy season in the GCM is problematic, the length of the average rainy season is closer to observations.

NEB displays more interannual variability in onset and withdrawal than the other regions, as shown by the large standard deviations in onset and withdrawal listed in Table 1, and shown in Fig. 9. NN-RegCM and ECRegCM have larger deviations in onset date, while the standard deviation for the onset for the GCM and withdrawal in all of the models are comparable to the observations. Despite the similar standard deviations in onset between the observations and the GCM, there is more year-to-year agreement in onset dates between the regional model simulations and the observations, as shown by the much larger correlations (Table 2).

Since rainfall in NEB is affected by SST anomalies in 

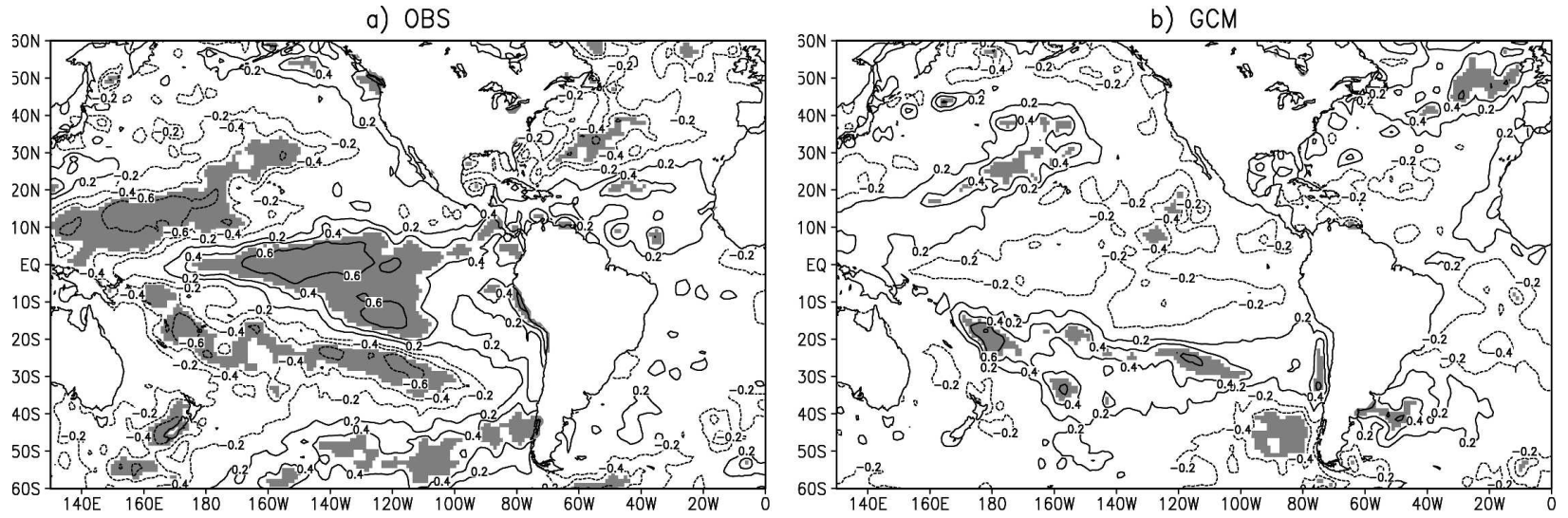

c) $\mathrm{NN}-\mathrm{RegCM}$

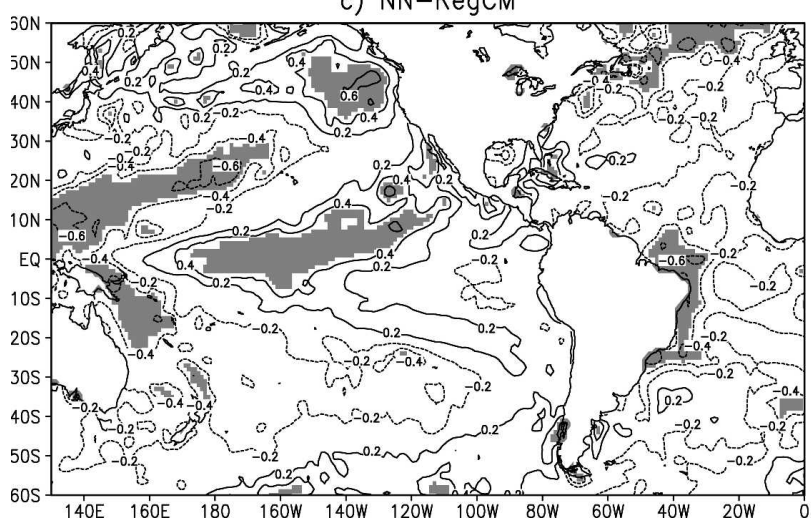

d) $\mathrm{EC}-\mathrm{Reg} \mathrm{CM}$

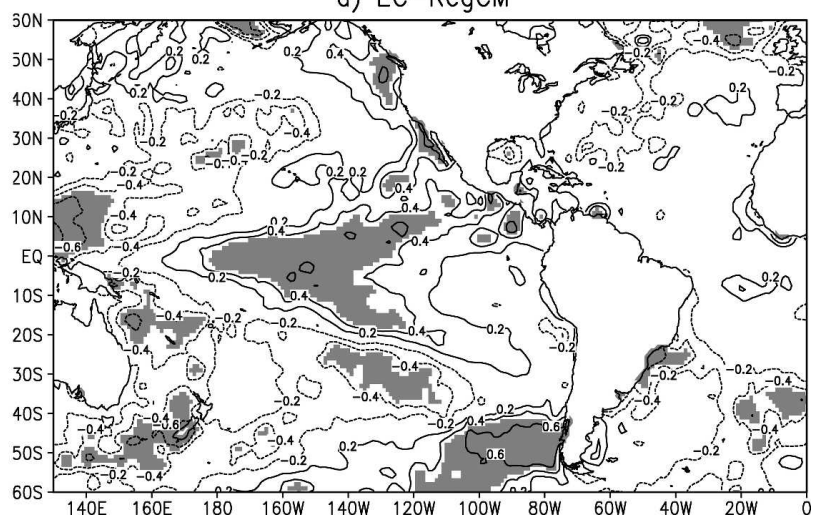

FIG. 8. Correlations between monthly SSTs and rainy season withdrawal date for (a) observations, (b) GCM, (c) NN-RegCM, and (d) EC-RegCM for MON, March 1983-March 2002. Contours are correlations (contour interval = 0.2, no 0 contour). Shaded areas are statistically significant at the 0.05 level.

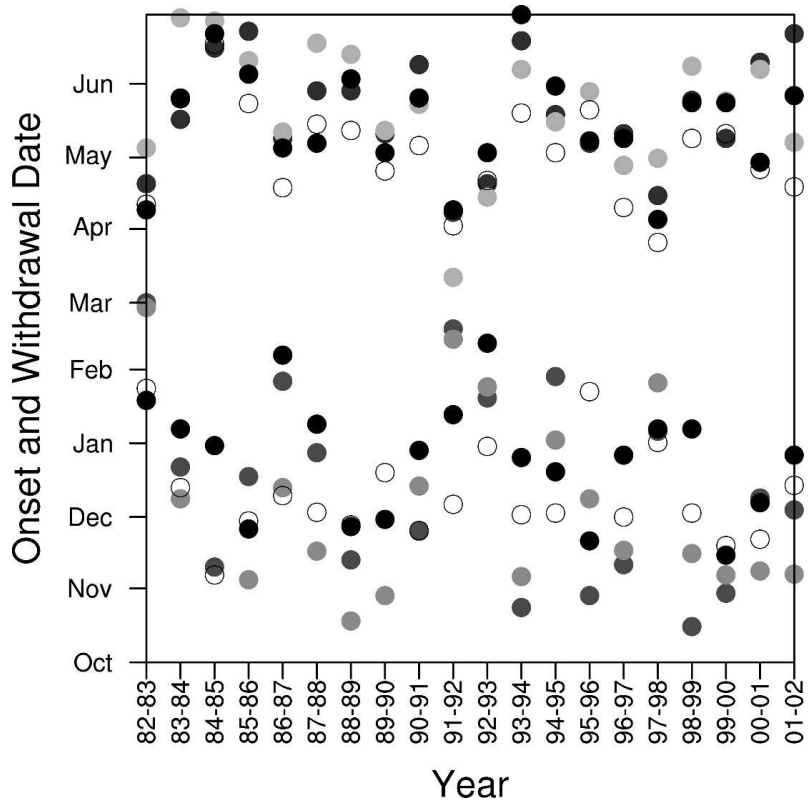

FIG. 9. Yearly onset and withdrawal dates for NEB, 1982-2002. Shading as in Fig. 6. the equatorial Pacific and Atlantic Oceans, and the model's predictive skill stems from these relationships, the model performance during warm and cold events is examined. The onset and withdrawal dates for the four cold and four warm event cases were calculated (Table $3)$. The observations show the average difference in onset between warm and cold events is 38 days. This difference was greatly exaggerated in the regional model. Although the average onset date during the warm events in the regional model simulations agrees well with observations, there are large differences in onset dates in several of the cold events ( $\sim 40$ days). In the GCM, onset occurs too early during both warm events and cold events.

\section{d. Dry spells}

In addition to knowledge of the timing of the rainy season, another aspect of the character of the rainy season is the occurrence of breaks, or dry spells. The frequency of dry spells 2-25 days in length occurring during the rainy season was calculated for NEB and SE. 
TABLE 3. Average onset, withdrawal, and length of rainy season during warm and cold ENSO events.

\begin{tabular}{|c|c|c|c|c|}
\hline SAMAZ & Obs & NN-RegCM & EC-RegCM & GCM \\
\hline \multicolumn{5}{|l|}{ Onset } \\
\hline Warm event & 22 Oct & $14 \mathrm{Sep}$ & $15 \mathrm{Sep}$ & 20 Oct \\
\hline Cold event & $12 \mathrm{Oct}$ & 2 Sep & $6 \mathrm{Sep}$ & 7 Oct \\
\hline \multicolumn{5}{|l|}{ Withdrawal } \\
\hline Warm event & $21 \mathrm{Apr}$ & $8 \mathrm{Apr}$ & $17 \mathrm{Apr}$ & 6 May \\
\hline Cold event & $23 \mathrm{Apr}$ & $22 \mathrm{Apr}$ & $14 \mathrm{Apr}$ & 11 May \\
\hline MON & Obs & NN-RegCM & EC-RegCM & GCM \\
\hline \multicolumn{5}{|l|}{ Onset } \\
\hline Warm event & 16 Oct & $23 \mathrm{Sep}$ & 29 Sep & 16 Oct \\
\hline Cold event & $23 \mathrm{Oct}$ & 29 Sep & 30 Sep & 16 Oct \\
\hline \multicolumn{5}{|l|}{ Withdrawal } \\
\hline Warm event & 13 May & $5 \mathrm{Apr}$ & $5 \mathrm{Apr}$ & $8 \mathrm{Apr}$ \\
\hline Cold event & $3 \mathrm{Apr}$ & 14 Mar & $20 \mathrm{Mar}$ & $12 \mathrm{Apr}$ \\
\hline NEB & Obs & NN-RegCM & EC-RegCM & GCM \\
\hline \multicolumn{5}{|l|}{ Onset } \\
\hline Warm event & 19 Jan & $5 \mathrm{Feb}$ & $28 \mathrm{Jan}$ & $26 \mathrm{Dec}$ \\
\hline Cold event & $13 \mathrm{Dec}$ & $2 \mathrm{Nov}$ & 26 Oct & $22 \mathrm{Nov}$ \\
\hline \multicolumn{5}{|l|}{ Withdrawal } \\
\hline Warm event & $15 \mathrm{Apr}$ & $21 \mathrm{Apr}$ & $22 \mathrm{Apr}$ & $7 \mathrm{Apr}$ \\
\hline Cold event & $3 \mathrm{Jan}$ & 28 May & 11 Jun & 20 May \\
\hline
\end{tabular}

We concentrate on these areas because they are major agricultural centers and because the ENSO signal is well established (Ropelewski and Halpert 1987, 1989). Dry spells are defined as consecutive days with rainfall below a given threshold. For this threshold we used the 10th percentile precipitation (Table 4) calculated over the rainy season (defined for each region) from 1982 to 2002. For example, if the observed precipitation for Northeast Brazil was lower than $0.82 \mathrm{~mm} \mathrm{day}^{-1}$ for 3 consecutive days, then this would be a 3-day dry spell in the observations. Note that the 10th percentile precipitation was computed separately for each model and the observations, as indicated in Table 4. For the ensembles (EC-RegCM and GCM), the 10th percentile precipitation value was computed relative to the distribution for daily precipitation for all three ensemble members inclusively.

\section{1) NortheAst BraziL}

The average number of dry spells per rainy season during 1982-2002 for NEB is shown in Fig. 10a. Obviously, dry spells of shorter length occur more often than longer dry spells. The regional model has a frequency similar to that of the observations, although the regional model tends to have more shorter-duration dry spells ( $2-3$ days) than are shown by the observations. Midlength (4-7 days) dry spells are underestimated by all of the models, in particular the NN-RegCM, which
TABLE 4. 10th percentile precipitation $\left(\mathrm{mm} \mathrm{day}^{-1}\right)$.

\begin{tabular}{cc}
\hline Region & 10th percentile \\
\hline NEB & 0.82 \\
Obs & 1.42 \\
NN-RegCM & 1.37 \\
EC-RegCM & 0.26 \\
GCM & \\
SE & 0.33 \\
Obs & 0.46 \\
NN-RegCM & 0.43 \\
EC-RegCM & 0.16 \\
GCM & \\
\hline
\end{tabular}

does not have sufficient dry spells in the 4-, 5-, and 7-day categories. At lengths greater than 8 days, the regional model tends to have more dry spells than are shown by the observations. The GCM underestimates the number of dry spells of lengths from 2 to 8 days (except for 6, when it has the same frequency), but overestimates dry spells of longer lengths.

Composites were also created for cold and warm events (Figs. 11a,b), defined in section 2a. The observations show a clear difference in the average number of dry spells of all lengths that occur during these periods, with far more dry spells during warm events. In addition, the observations show more dry spells of longer lengths; for example, there are more dry spells on average of 8 days length than there are 3-, 4-, 6-, or 7-day lengths. There are no observed dry spells longer than 3 days in the cold event composite. The ECRegCM and NN-RegCM capture this dearth of dryness, as they show some occurrences of 4- and 5-day dry spells, respectively, while the GCM has some dry spells in the 7-9-day categories.

\section{2) Southeast South America}

The dry spell frequency (Fig. 10b) was computed for SE as for NEB. Compared to the northeast, the observations show more shorter-duration dry spells, but fewer midlength dry spells. The regional model underestimates the number of shorter dry spells and overestimates somewhat the number of midlength dry spells. The observations show a few occurrences of longer dry spells (8-9 days) during the 20 rainy seasons, which are simulated by the regional model (especially the ECRegCM), but not by the GCM.

The difference between the warm episode and cold episode composites is somewhat smaller over SE than NEB, as shown in Figs. 11c,d. There are more dry spells during cold events, and the only dry spells longer than 4 days occur in a cold event year. The GCM and the EC-RegCM do not perform well here; in fact, in some 

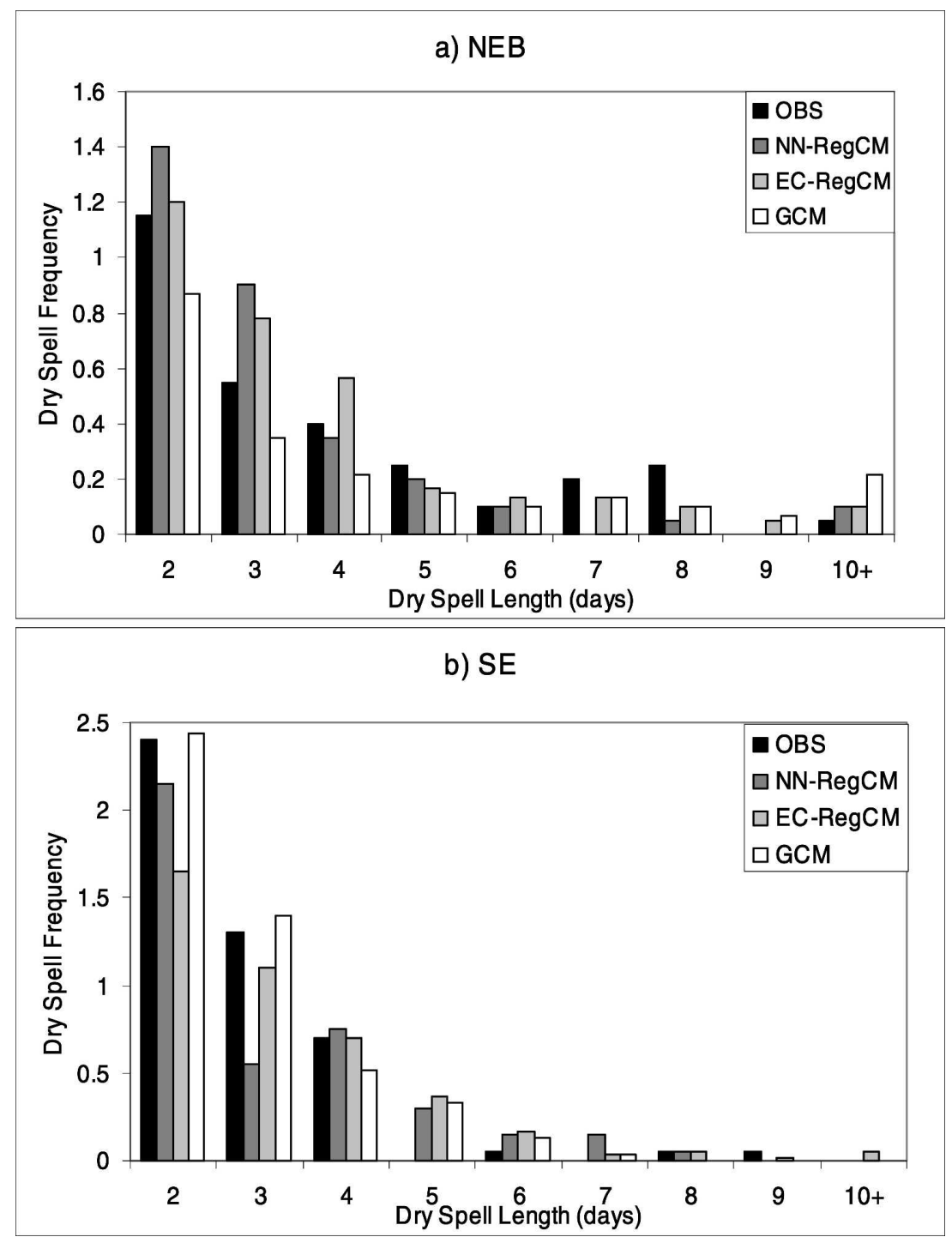

FIG. 10. Dry spell frequency, 1982-2002 for (a) NEB and (b) SE. Shading as in Fig. 3.

cases they simulate more dry spells in warm events versus cold events. This is not surprising considering that interannual variability due to ENSO is not well represented by the GCM (and via the lateral boundary conditions, by the EC-RegCM) in this region (Seth et al. 2006).

\section{Conclusions}

We examine the potential for an experimental nested prediction system to improve the simulation of subseasonal rainfall statistics over the driving GCM. Results from a 20-yr retrospective study (rainy seasons between January 1982 and December 2002) with four ensemble members were analyzed for five regions in tropical and subtropical South America: NAMAZ, SAMAZ, NEB, MON, and SE. The regional model and the GCM are able to replicate the observed modal intensity (the category with the maximum number of events) of daily rainfall in most regions. Both the regional model and the GCM tend to underestimate (overestimate) the frequency of shorter (longer) dry spells, although the differences in dry spell frequency during warm events and cold events are fairly well simulated for NEB.

The analysis of the timing of the rainy season indicates that the regional model errors are smaller than those shown by the GCM over NEB. In addition, for NEB the strong interannual variability in the timing of the rainy season is better simulated by RegCM3. Over the interior of the continent, the observations show on- 
a) NEB - COLD ENSO EVENTS

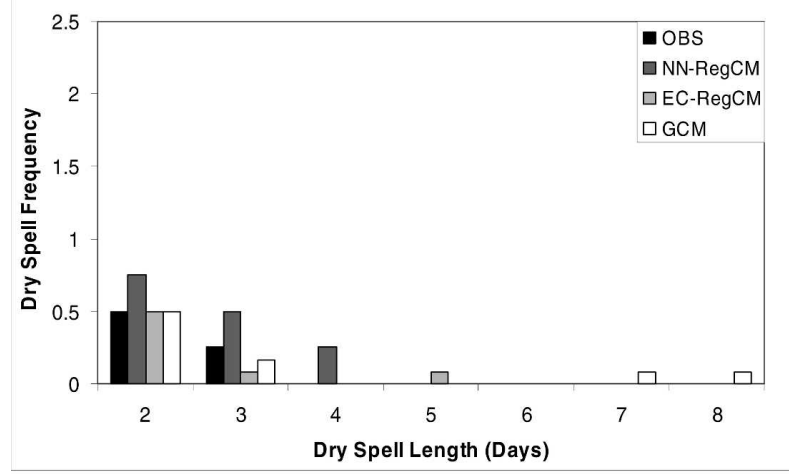

b) NEB - WARM ENSO EVENTS

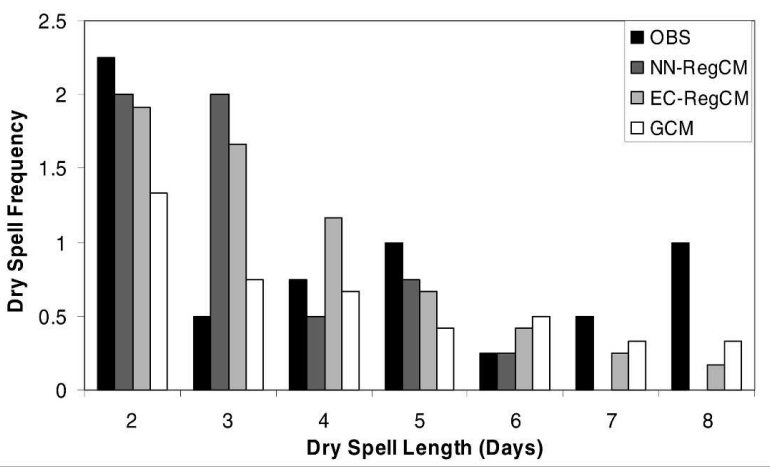

c) SE - COLD ENSO EVENTS

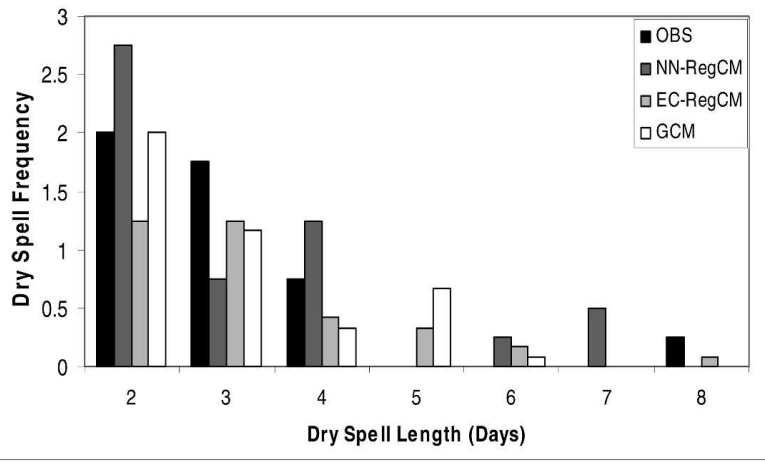

d) SE - WARM ENSO EVENTS

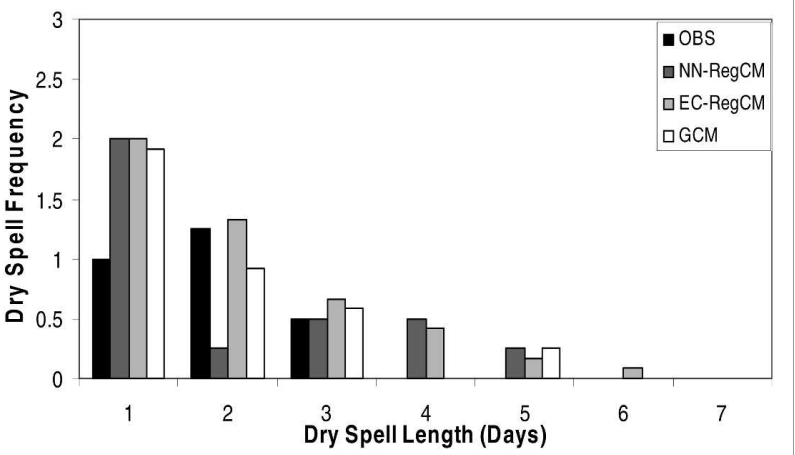

FIG. 11. Dry spell frequency, 1982-2002 for NEB during (a) cold and (b) warm ENSO events and for SE during (c) cold and (d) warm ENSO events. Shading as in Fig. 3.

set occurring first over the MON region and then spreading northward into SAMAZ, in agreement with the findings of Liebmann and Marengo (2001) and Liebmann et al. (2007). While the GCM is able to correctly simulate the timing of the rainy season over the SAMAZ and MON areas, the regional model consistently displays an early onset and withdrawal, regardless of the lateral boundary forcing. Correlations between the onset and withdrawal date and SSTs revealed a strong relationship between withdrawal date in the MON region-an area for which strong relationships between SSTs and rainfall has not been established-and SSTs in the equatorial Pacific, with higher-than-average SSTs associated with late withdrawal. This relationship was captured by the regional model but not by the GCM.

Despite some problems with the simulation of the large-scale climatological features (Seth et al. 2006), the regional model appears to perform as well as, and in a few cases better than, the GCM in simulating the subseasonal precipitation statistics. However, there are also some measures for which the GCM outperforms the regional model. Given this mix of results, the nested regional modeling system does not offer sufficient added value to be used in an operational setting at the present time. However, recent experiments performed with the recently added Massachusetts Institute of Technology-Emanuel convective parameterization (Emanuel 1991; Emanuel and Zivkovic-Rothman 1999) in RegCM3 have shown substantial improvements in the simulation of the annual cycle over South America (Seth et al. 2006; Pal et al. 2007). Preliminary results indicate that this scheme greatly reduces the early bias in the timing of the rainy season over the SAMAZ and MON regions. These results further illustrate that higher resolution alone is insufficient to capture subseasonal statistics such as rainy season onset, withdrawal, and dry spells. Improved understanding of the physical processes, particularly related to convection, must be developed and implemented at high resolution in order to achieve added value in tropical regions.

Acknowledgments. We thank four anonymous reviewers, whose constructive comments helped us to improve and clarify the manuscript. Ms. Huilan Li helped to develop the interface between the ECHAM GCM and $\mathrm{RegCM} 3$. The authors would also like to thank the 
Max-Planck Institute for Meteorology (Hamburg, Germany) for making the ECHAM GCM available to the International Research Institute for Climate and Society (IRI). This research was funded in part by NOAA (Award NA16GP2029) and the International Research Institute for Climate and Society (Grant NA050AR4311004). The views expressed herein are those of the authors and do not necessarily reflect the views of NOAA or any of its subagencies.

\section{REFERENCES}

Arakawa, A., and W. H. Schubert, 1974: Interaction of a cumulus cloud ensemble with the large scale environment, Part I. $J$. Atmos. Sci., 31, 674-701.

Barnston, A. G., S. J. Mason, L. Goddard, D. G. DeWitt, and S. E. Zebiak, 2003: Multimodel ensembling in seasonal climate forecasting at IRI. Bull. Amer. Meteor. Soc., 84, 17831796.

Berbery, E. H., and V. R. Barros, 2002: The hydrologic cycle of the La Plata Basin in South America. J. Hydrometeor., 3, 630-645.

Bonan, G. B., K. W. Oleson, M. Vertenstein, S. Levis, X. Zeng, Y. Dai, R. E. Dickinson, and Z.-L. Yang, 2002: The land surface climatology of the Community Land Model coupled to the NCAR Community Climate Model. J. Climate, 15, 31233149.

Carvalho, L. M. V., C. Jones, and B. Liebmann, 2004: The South Atlantic convergence zone: Intensity, form, persistence, and relationships with intraseasonal to interannual activity and extreme rainfall. J. Climate, 17, 88-108.

Emanuel, K. A., 1991: A scheme for representing cumulus convection in large-scale models. J. Atmos. Sci., 48, 2313-2329.

—_, and M. Zivkovic-Rothman, 1999: Development and evaluation of a convection scheme for use in climate models. $J$. Atmos. Sci., 56, 1766-1782.

Figueroa, S. N., and C. A. Nobre, 1990: Precipitation distribution over central and western tropical South America. Climanálise, 5, 36-40.

Fouquart, Y., and B. Bonnel, 1980: Computation of solar heating of the Earth's atmosphere: A new parameterization. Beitr. Phys. Atmos., 53, 35-62.

Gan, M. A., V. E. Kousky, and C. F. Ropelewski, 2004: The South American monsoon circulation and its relationship to rainfall over west-central Brazil. J. Climate, 17, 47-66.

González, M., and V. Barros, 2002: On the forecast of the onset and end of the convective season in the Amazon. Theor. Appl. Climatol., 73, 169-187.

Grell, G., 1993: Prognostic evaluation of assumptions used by cumulus parameterizations. Mon. Wea. Rev., 121, 764-787.

_ _ J. Dudhia, and D. R. Stauffer, 1994: Description of the fifth generation Penn State/NCAR Mesoscale Model (MM5). Tech. Rep. TN-398+STR, NCAR, Boulder, CO, 121 pp.

Grimm, A. M., V. R. Barros, and M. E. Doyle, 2000: Climate variability in southern South America associated with El Niño and La Niña events. J. Climate, 13, 35-58.

Hastenrath, S., and L. Heller, 1977: Dynamics of climatic hazards in Northeast Brazil. Quart. J. Roy. Meteor. Soc., 103, 77-92.

Horel, J. D., A. N. Hahmann, and J. E. Geisler, 1989: An investigation of the annual cycle of the convective activity over the tropical Americas. J. Climate, 2, 1388-1403.
Kalnay, E., and Coauthors, 1996: The NCEP/NCAR 40-Year Reanalysis Project. Bull. Amer. Meteor. Soc., 77, 437-471.

Kodama, Y.-M., 1992: Large-scale common features of subtropical precipitation zones (the Baiu frontal zone, the SPCZ, and the SACZ). Part I: Characteristics of the subtropical frontal zones. J. Meteor. Soc. Japan, 70, 813-836.

_, 1993: Large-scale common features of subtropical precipitation zones (the Baiu frontal zone, the SPCZ, and the SACZ). Part II: Conditions of the circulation for generating the STCZs. J. Meteor. Soc. Japan, 71, 581-610.

Kousky, V. E., 1979: Frontal influences on Northeast Brazil. Mon. Wea. Rev., 107, 1140-1153.

- 1988: Pentad outgoing long wave radiation climatology for the South America sector. Rev. Brasil. Meteor., 3, 217-231.

— monitoring and assessing the ENSO cycle. Wea. Forecasting, 22, 353-371.

Lemos, M. C., T. J. Finan, R. W. Fox, D. R. Nelson, and J. Tucker, 2002: The use of seasonal climate forecasting in policymaking: Lessons from Northeast Brazil. Climatic Change, 55, 479507.

Li, W., R. Fu, and R. E. Dickinson, 2006: Rainfall and its seasonality over the Amazon in the 21st century as assessed by the coupled models for the IPCC AR4. J. Geophys. Res., 111, D02111, doi:10.1029/2005JD006355.

Liebmann, B., and J. A. Marengo, 2001: Interannual variability of the rainy season and rainfall in the Brazilian Amazon basin. J. Climate, 14, 4308-4318.

- , and D. Allured, 2005: Daily precipitation grids for South America. Bull. Amer. Meteor. Soc., 86, 1567-1570.

_, G. N. Kiladis, J. A. Marengo, T. Ambrizzi, and J. D. Glick, 1999: Submonthly convective variability over South America and the South Atlantic convergence zone. J. Climate, 12, 1877-1891.

— S. J. Camargo, A. Seth, J. A. Marengo, L. M. V. Carvalho, D. Allured, R. Fu, and C. S. Vera, 2007: Onset and end of the rainy season in South America in observations and the ECHAM 4.5 Atmospheric General Circulation Model. J. Climate, 20, 2037-2050.

Marengo, J. A., B. Liebmann, V. E. Kousky, N. P. Filizola, and I. C. Wainer, 2001: Onset and end of the rainy season in the Brazilian Amazon basin. J. Climate, 14, 833-852.

—, M. W. Douglas, and P. L. Silva Dias, 2002: The South American low-level jet east of the Andes during the 1999 LBA-TRMM and LBA-WET AMC campaign. J. Geophys. Res., 107, 8079, doi:10.1029/2001JD001188.

_, W. R. Soares, C. Saulo, and M. Nicolini, 2004: Climatology of the low-level jet east of the Andes as derived from NCEPNCAR reanalyses: Characteristics and temporal variability. J. Climate, 17, 2261-2280.

Mearns, L. O., F. Giorgi, L. McDaniel, and C. Shields, 1995: Analysis of daily variability of precipitation in a nested regional climate model: Comparison with observations and doubled $\mathrm{CO}_{2}$ results. Global Planet. Change, 10, 55-78.

Morcrette, J.-J., L. Smith, and Y. Fouquart, 1986: Pressure and temperature dependence of the absorption in longwave radiation parameterizations. Beitr. Phys. Atmos., 59, 455-469.

Moura, A. D., and S. Hastenrath, 2004: Climate prediction for Brazils Nordeste: Performance of empirical and numerical modeling methods. J. Climate, 17, 2667-2672.

Nobre, P., A. D. Moura, and L. Sun, 2001: Dynamical downscaling of seasonal climate prediction over Nordeste Brazil with 
ECHAM3 and NCEP's regional spectral models at IRI. Bull. Amer. Meteor. Soc., 82, 2787-2796.

Nogues-Paegle, J., and Coauthors, 2002: Progress in pan American CLIVAR research: Understanding the South American monsoon. Meteorologica, 27, 3-32.

Paegle, J., 1998: A comparative review of South American lowlevel jets. Meteorologica, 23, 73-81.

Pal, J. S., and Coauthors, 2007: Regional climate modeling for the developing world: The ICTP RegCM3 and RegCNET. Bull. Amer. Meteor. Soc., in press.

Palmer, T. N., and Coauthors, 2004: Development of a European Multimodel Ensemble for Seasonal-to-Interannual Prediction (DEMETER). Bull. Amer. Meteor. Soc., 85, 853-872.

Rauscher, S. A., A. Seth, J.-H. Qian, and S. J. Camargo, 2006: Domain choice in an experimental nested modeling prediction system for South America. Theor. Appl. Climatol., 86, 229-246.

Reynolds, R. W., N. A. Rayner, T. M. Smith, D. C. Stokes, and W. Wang, 2002: An improved in situ and satellite SST analysis for climate. J. Climate, 15, 1609-1625.

Roeckner, E., and Coauthors, 1996: The atmospheric general circulation model ECHAM-4: Model description and simulation of present day climate. Tech. Rep. 218, Max Planck Institute for Meteorology, $90 \mathrm{pp}$.

Ropelewski, C. F., and M. S. Halpert, 1987: Global and regional scale precipitation patterns associated with the El El Niño/ Southern Oscillation. Mon. Wea. Rev., 115, 1606-1626.

_, and —, 1989: Precipitation patterns associated with the high index phase of the Southern Oscillation. J. Climate, 2, 268-284.

Seth, A., M. Rojas, B. Liebmann, and J.-H. Qian, 2004: Daily rainfall analysis for South America from a regional climate model and station observations. Geophys. Res. Lett., 31, L07213, doi:10/1029/2003GL019220.
—, S. A. Rauscher, S. J. Camargo, J.-H. Qian, and J. S. Pal, 2006: RegCM regional climatologies for South America using Reanalysis and ECHAM global model driving fields. Climate Dyn., 28, 461-480.

Sun, L., D. F. Moncunill, H. Li, A. D. Moura, and F. A. S. Filho, 2005: Climate downscaling over Nordeste, Brazil, using the NCEP RSM97. J. Climate, 18, 551-567.

,,,,----- , and S. E. Zebiak, 2006: An operational dynamical downscaling prediction system for Nordeste Brazil and the 2002-04 real-time forecast evaluation. J. Climate, 19, 1990-2007.

Tiedtke, M., 1989: A comprehensive mass flux scheme for cumulus parameterization on large scale models. Mon. Wea. Rev., 117, 1779-1800.

Vera, C., P. K. Vigliarolo, and E. H. Berbery, 2002: Cold season synoptic-scale waves over subtropical South America. Mon. Wea. Rev., 130, 684-699.

_ , and Coauthors, 2006: The South American low-level jet experiment. Bull. Amer. Meteor. Soc., 87, 63-77.

Virji, H., 1981: A preliminary study of summertime tropospheric circulation patterns over South America estimated from cloud winds. Mon. Wea. Rev., 109, 599-610.

Wang, H., and R. Fu, 2002: Cross-equatorial flow and seasonal cycle of precipitation over South America. J. Climate, 15, 1591-1608.

Xie, P., and P. A. Arkin, 1996: Analyses of global monthly precipitation using gauge observations, satellite estimates, and numerical model predictions. J. Climate, 9, 840-858.

Zhou, J., and K.-M. Lau, 1998: Does a monsoon climate exist over South America? J. Climate, 11, 1020-1040.

$\longrightarrow$, and — 2002: Intercomparison of model simulations of the impact of 1997/98 El Niño on South American summer monsoon. Meteorologica, 27, 99-116. 